\title{
Relationship between Fluor Concentration and Structure Pattern of Enamel Prism in Enamel Surface after Coffee and Black Tea Exposure
}

\author{
Abdillah Imron Nasution, Basri A Gani, Rini Maulida Pospos
}

\begin{abstract}
Coffee and tea are often consumed by Indonesian and Aceh people. Based on previous research reported that concentration of fluor in coffee and tea affects pattern structure of enamel prism. Currently, little explanation about relationship between fluor concentrations and pattern structure of enamel prism in enamel surface after coffee and tea drinking water exposure. The purpose of this study is to explain relationship between fluor concentrations and pattern structure of enamel prism in enamel surface after coffee and tea drinking water exposure.
\end{abstract}

\begin{abstract}
Materials and methods: Eight maxillary premolars were divided into control and treatment group. P ositive control group exposure to $\mathrm{NaCl} 0.9 \%$, negative control group exposure to sulfuric acid $50 \%$, treatment groups are exposure to coffee and tea drinking water. This study conducted by scanning electron microscopy/ energy dispersive X-ray spectroscopy (SEM/EDX). Data analysis is descriptive qualitative.
\end{abstract}

Results: Fluor in tea increases the density of the enamel prism structure pattern. Surface enamel that exposed to tea has described better arrangement of enamel prism pattern than enamel surface that exposed to coffee.

Conclusion: Fluor concentration in drinking water has relationship with structure patterns of enamel prism. The structure patterns of enamel prism that exposed to tea have better arrangement than enamel that exposed to coffee.

Keywords: Enamel prism, Fluor, SEM/EDX.

How to cite this article: Nasution Al, Gani BA, Pospos RM. Relationship between F luor Concentration and S tructure P attern of Enamel P rism in E namel Surface after C offee and Black Tea Exposure. World J Dent 2012;3(4):284-289.

\section{Source of support: Nil}

Conflict of interest: None declared

\section{INTRODUCTION}

Coffee and tea is a type of drink that has long been known and widely consumed worldwide, including in Indonesian. ${ }^{1}$ Commerce market was estimate the level of coffee consumption in Indonesia is an attractive market. A ccording to Food and $A$ griculture Organization of the $U$ nited $N$ ations (FAO) in several countries, including Indonesia, the consumption of black tea is more than 140 thousand tons per year. ${ }^{2}$ Some of chemical compound in both beverages can improve the taste of coffee and tea. ${ }^{3,4}$

Factly, scientific studies conducted to examine coffee and tea. ${ }^{3-5}$ Published studies reported that coffee and tea has heal th benefits for the human body. B oth of these drinks considered as a beverage that can reduce risk of some diseases including the risk of caries. ${ }^{3-7}$ Research results in 2009 in Bengaluru reported the score of decayed missing filled surface (DM FS) in people who do not consume coffee is 4 , whereas in people who consumed coffee is $2.9{ }^{4}$ Research data from research of dental caries prevalence 2001 in London, England, also showed that the prevalence of caries in people consumed tea are lower than people do not consumed tea. ${ }^{7}$

Fluor can strengthening an enamel prism structure pattern and assist the remineralization process in the structure of enamel prism to increase density of enamel surface. ${ }^{8,9} \mathrm{U}$ nited States D epartment of A griculture $\mathrm{N}$ ational Fluoride Database (USDA) reported the concentration of fluor in coffee and tea is difference. ${ }^{10}$ Fluor in arabica is 0.52 to $1.25 \mathrm{mg}$ per liter, while in black tea is $9 \mathrm{mg}$ per liter. ${ }^{11} \mathrm{~B}$ ased on the results of studies using fluoride-specific electrode (FSE) reported that there are differences in concentration of fluor in coffee and tea, but not significant. ${ }^{12}$

Enamel is structured by enamel prism which formed by crystal apatite. ${ }^{13,14}$ The apatite is $\mathrm{Ca}_{10}\left(\mathrm{PO}_{4}\right)_{6}(\mathrm{X})$. The $(\mathrm{X})$ elements could be hydroxyl, fluor, carbonate or magnesium. ${ }^{15,16}$ The apatite is very tolerant from substitutions. E namel structurewhich formed by fluor apatite (FA) demonstrate a different structure than $\mathrm{HA} \cdot{ }^{17}$ The fluor substitution indicated the change of apatite crystal structure as enamel former. ${ }^{18}$ Research study using scanning electron microscopy (SEM) known that fluor has significant effect on apatit. ${ }^{19}$ Substitution of fluor into apatite, influence the pattern of the surface of the prism structure. ${ }^{8,9}$

Based on fluor content in coffee and tea can affect the macroscopic of enamel surface, thatimportantto conductstudy regarding to relationship between structure of prism patterns and fluor concentration in enamel surface after exposure to coffee and tea. The aim of this study is to explain the relationship between patterns of enamel prism and fluor concentration in enamel surface after exposure to coffee and tea.

\section{MATERIALS AND METHODS}

This laboratory experimental conducted at Laboratory of $M$ etallurgy Faculty of Engineering U niversity of Indonesia and Laboratory of Chemistry Faculty of M athematics and Natural Sciences U niversity of Syiah K uala. This research was conducted in M arch 2011. 
Specimens are eight premolars that collected from orthodontic treatment that extracted from various dentistry clinics in B anda A ceh-Indonesia. The specimens were free from dental caries, abrasion, attrition and erosion. The specimens were randomly separated into four groups: Control positive, control negative (applied with $50 \%$ sulfuric acid), and two treatment groups (applied with $20 \mathrm{gm}$ coffee and tea in 150 cc water). Each group consisted of two specimens: Every group wrapped in ringer-cotton for storage.

SEM analysis conducted with a secondary electron emission for image-acquisition of both surfaces of the specimens. Two separate magnifications were used: $20 x$ and 500X, EDX/EDS analysis conducted with backscattered emission, i-Probe 380 to $450 \mathrm{pA}$, accelerating voltage $12 \mathrm{kV}$. Wavelength is under $1,000 \mathrm{~mA}$. Result analysis is fluor percentage rate of EDX/EDX standard.

\section{RESULTS}

Positive control (Fig. 1) should that exposure with 0.9\% $\mathrm{NaCl}$ solution based on SEM observation (magnification $1,500 x$ ), showed enamel prism structure in regular pattern with head and tail of enamel rods in normal appearance.
Generally, the pattern of enamel prism in working distance (WD) $12 \mathrm{~mm}$ was $82 \%$ have good density. The picture showed more clearly in magnification of 3,000x (Fig. 1). The pattern of enamel rods showed a key hole shape. Picture al so showed demarcated line on peripheral, no gaps on rod sheath, and rod cores not porous. EDX analysis of positive control showed ratio between calcium and phosphate is 2:1 ( $\mathrm{Ca}=39.83 \%$ and $\mathrm{p}=22.97 \%)$. EDX analysis showed fluor content as $12.18 \% *$. Sign $(*)$ that found on fluor concentration in EDX is mean fluor concentration on the surface of enamel equal to zero. EDX analysis can be see on Table 1 below.

Scanning electron microscopy of negative control in magnification $1,500 \times$ that exposured with $50 \%$ sulfuric acid for 180 minutes showed irregularly pattern of enamel prism. Enamel prism mainly showed a damage area on part of head of enamel prism. The pattern of the enamel showed prismless zone. Picture in magnification 3,000x (Fig. 2) generally showed no demarcated line on peripheral part, rod sheath showed fibrous-like and indicate damage of enamel as well as highly porous on part of rod core enamel. Some areas showed decreasing in enamel density. SEM picture on WD $12 \mathrm{~mm}$ of showed only $14 \%$ undamaged

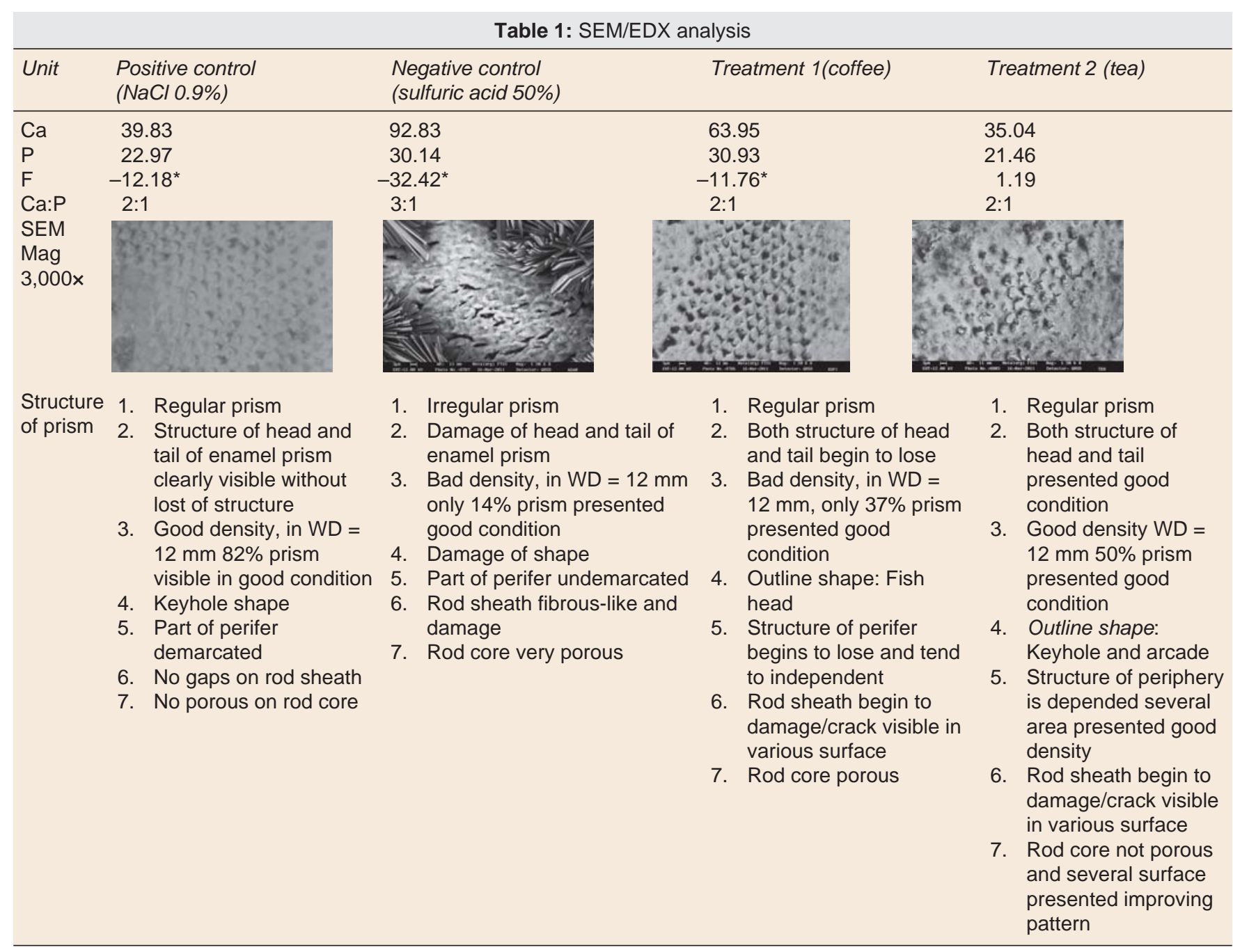




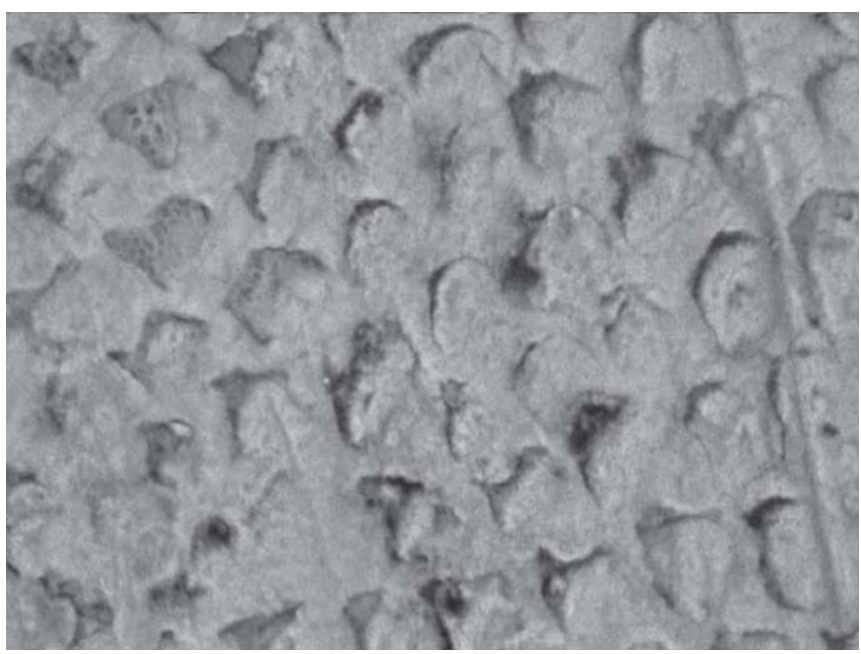

Fig. 1: SEM picture of positive control (Magnification: $3,000 x$ )

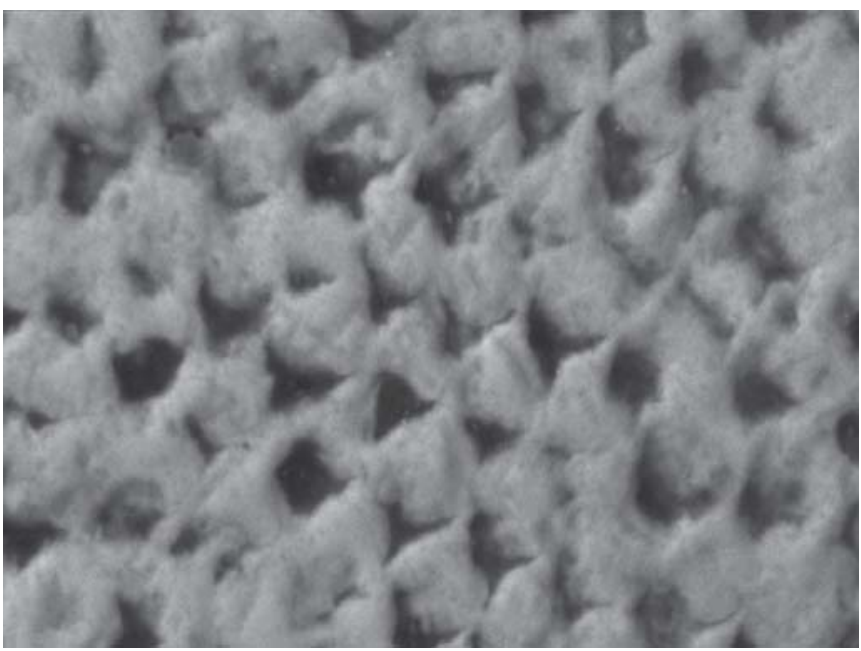

Fig. 3: SEM picture of coffee exposure specimen (Magnification: $3,000 \times$ )

enamel prism. EDX analysis of negative control showed ratio between calcium and phosphate to be $3: 1(\mathrm{Ca}=92.83 \%$ and $p=30.14 \%)$. EDX analysis showed fluor is $-32.42 \%$.

SEM of coffee exposure in 15 minutes in magnification $1,500 \times$ showed a pattern of enamel rods that arranged in head and tail of enamel rods even in regular shape but it was beginning to loss of structure. Prism pattern on the enamel surface showed decreasing of density of enamel. SEM picture on WD $=12 \mathrm{~mm}$ of the pattern of enamel prism shows only $37 \%$ in clear condition. SEM picture in magnification 3,000 (Fig. 3) generally showed visible the outline shape that resembles of fish scale. Some areas indicate porous areas. The peripheral parts indicate lost of rod structure. Generally, damaged pattern occurred in the head of rod sheath. This picture shows a decrease of enamel density as show $n$ in negative control. EDX analysis of coffee exposure showed ratio between calcium and phosphate is $2: 1(\mathrm{Ca}=63.95 \%$ and $\mathrm{p}=30.93 \%)$. EDX also showed fluor is $-11.76 \% *$.

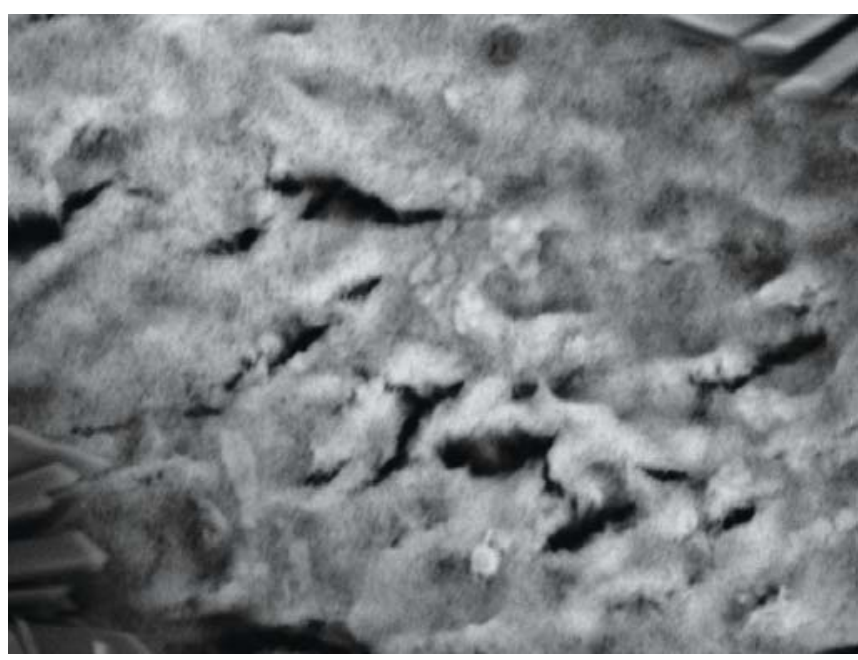

Fig. 2: SEM picture of negative control (Magnification: $3,000 \times$ )

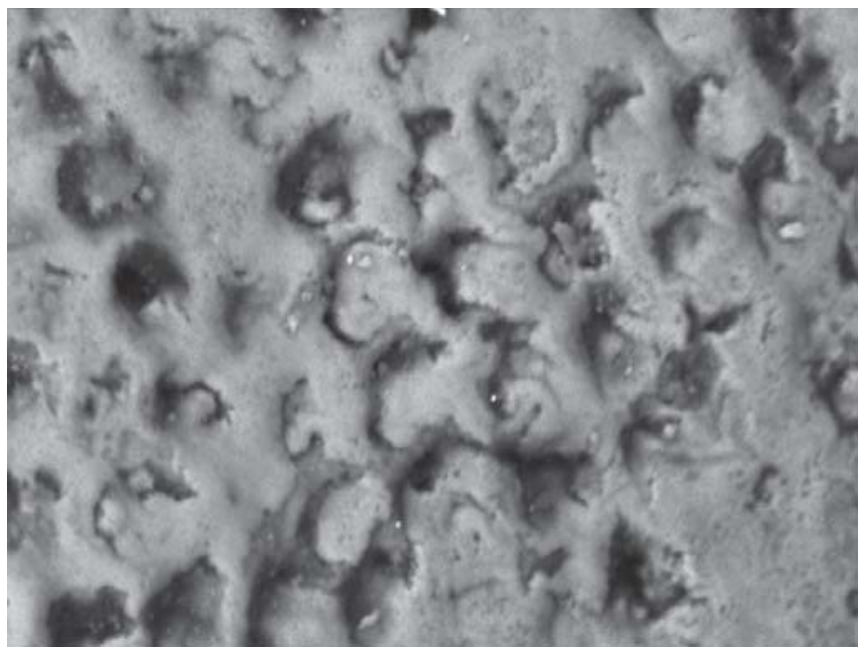

Fig. 4: SEM picture of tea exposure specimen

(Magnification: $3,000 \times$ )

SEM of tea exposure in 15 minutes in magnification $1,500 \times$ showed the pattern of prism structure that arranged on a regular shape with a prism shape with head and tail is still clearly visible. Generally, the pattern of prism structures showed an increasing of enamel density. Picture of the pattern of the enamel surface showed pattern of the surface structure same as enamel prism on positive control. D ensity relatively $50 \%$ in good condition as shown in WD $=12 \mathrm{~mm}$. SEM picture in magnification 3,000x (Fig. 4) showed the enamel prism structure as keyhole shape. SEM generally show the demarcated peripheral, no gaps on rod sheath, and rod cores are not porous. EDX of tea exposure showed ratio between calcium and phosphate is $2: 1$ ( $\mathrm{Ca}=35.04 \%$ and $p=21.46 \%)$. EDX also showed fluor is $1.19 \%$.

\section{DISCUSSION}

Enamel consists of a prism that extends from the dentinoenamel junction (DEJ) to outer surface of enamel. 
Each prism consists of crystal hydroxy apatite..$^{20}$ Calcium and phosphate ions dominate prismatic structures. From the results of this study, it is known that calcium and phosphate ratio is 2:1. A ccording to Robinson et al study, it was reported that average ratio of calcium and phosphorus in the enamel surface is $2: 1 .^{20}$

SEM /EDX observations in this study suggests that the negative control group ( $50 \%$ sulfuric acid for 180 minutes) shown demineralization has occurred in this specimen. The structural of chemical properties of the mineral apatite allow the substitution of ions in enamel, especially calcium and hydroxyl. The mineral content of prism structure determine pattern the surface of the enamel. Little fluor content on the surface of enamel indicates worse prismatic structure. Decreasing of fluor contentin enemal surface were initiating theformation of cavities (caries) and demineral ization. ${ }^{20} \mathrm{This}$ condition, greatly affects the pattern of thestructure of enamel prism. ${ }^{21} \mathrm{M}$ any scientific studies have proven that fluoride is

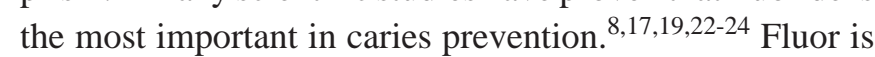
believed to be able to strengthening the structure of the enamel because fluoride is able to stimulate the remineralization. ${ }^{17}$

The results of this study proved that fluor which exposed on the enamel surface after tea exposure improving the structure of enamel prism pattern, especially in rod core and peripheral rods. A ccording to Simpson et al that reported there is an interaction between the fluor in black tea against hydroxyl apatite. ${ }^{21}$ Several studies also support this result that the incorporation of fluor ions into the apatite are significantly effective in inhibiting demineralization. ${ }^{17,20}$ From these studies obtained a conclusion that the decrease in the amount of minerals, especially fluor ions affect the structure of the prism. However, these results differ with previous research that reported fluor substitution on hydroxyl ions cannot affect the enamel surface and does not prevent demineralization. ${ }^{17}$

The surface of enamel prism that exposed to fluor showed more consistent morphological structure. Fluor acts as a catalyst and increases the level of formation of hydroxy apatite (HA) into fluor hydroxy apatite (FHA) or fluor apatite (FA) ${ }^{16}$ This substitution was stimulated, the crystal size becomes smaller. A s a result, an increasing number of crystals after fluoride application will increase enamel prism structure and tend to be more resistant to acid. Similar with this study, previous study reported that fluor affects the surface structure of enamel prism pattern. ${ }^{24}$

Result of this study was also supported by the results of research by 0 kazaki. They proved that there is a significant influence on hydroxy apatite after the incorporation of fluor ions. Incorporation of fluor ions into apatite crystal size may improve the enamel crystal. Substitution of fluor ions into apatite crystals was reported can stimulate the increasing of enamel prism structural. ${ }^{17}$ This answer is in line with result of research that was conducted by various researches. ${ }^{17,25,26}$

A mineral component in enamel was substitutioned of calcium hydroxyl apatite. Hydroxy apatite compounds $\mathrm{CA}_{10}\left(\mathrm{PO}_{4}\right)_{6}(\mathrm{X})$. The $\mathrm{X}$ mean in specimen were packed by hydroxyl ions. ${ }^{15,16} \mathrm{Hydroxyl}$ ions are highly susceptible to substitution by some other ions, such as fluor. As apatite, FHA and FA were very tolerant of substitution of ions in the lattice of crystal apatite. The substitution of other ions into apatite will improve shape and physical properties of hydroxy apatite. ${ }^{27}$ The number of hydroxyl ions 20 to $30 \%$ less than the apatite. D efects in hydroxy apatite are frequent, particularly the trend and experienced demineralization soluble at low pH (acid). ${ }^{20}$ Enamels that have remineralization is more resistant to acid than is healthy because enamel is not easily soluble fluorine minerals and crystals deposit back enamel. ${ }^{28}$

Fluor is the most electronegative atom and a reactive element. The substitution of fluor ions into apatite will replace hydroxyl ions because fluor has a smaller atom than hydroxyl. Two ions that are similar, have same components, and have the smaller atom can lead the substitution of hydroxy apatite crystal lattice and thus affects the pattern of prism structure of enamel. ${ }^{27}$ Increased prism structure can occur due to an increase in the amount of fluor. The fluor position is in c-axis in crystal apatite. This structure was closer to calcium that causes the energy of crystal that required in apatite composition becomes lower. This condition made crystal structure more stable than apatite that arranged by hydroxyl on c-axis. This condition was proved that substitution of fluor into hydroxyl position made crystal structure becomes more resistant to acid. ${ }^{20}$

The results of this study al so showed the different pattern of the prism structure after exposure to coffee and tea. Prism structure on the enamel surface after exposure to coffee is more likely to show demineralization than tea exposure. The prism structure after exposure to coffee for 15 minutes showed the structure of prism with the peripheral part of independent and surface fibrous-like texture. A ccording to research results of Nicholl, Judd and A nsell, the exposure of acid into enamel would influence the demineralization. The prism damage in the peripheral after exposure to coffee is a reaction of prism to acid attack. ${ }^{26} \mathrm{As}$ shown by SEM, the prism pattern more has porous with a destruction of half prism. That usually occurs in the head and rod sheath. Coffee, factly is an acidic consumption that initiated demineralization of enamel. 
The statement was similar with the research of Simmelink and A brigo on morphology and decalcification hydroxy apatite crystals exposure with acid in different duration..$^{29}$ This study also not contradict with the results that stated there are different reactions in the peripheral regions (rod periphery) to acid attack into enamel. ${ }^{26}$ SEM of the prism structure after exposure to sulfuric acid and coffee visible organic material (enamelin) in interrod higher than other specimen. A tlow pH (acid) that contained enamel often visible organic material on tooth surface, after exposure by acid. ${ }^{20}$

Results of this study also obtained picture of normal prism structure as shown in Figure 1 on positive control. SEM observations at 1,500 x magnification show the pattern of prism structure without damage. Detailed description that shown in magnification $3000 \times$ looks prisms are interconnected with each other to form a keyhole-like outline, hexagonal, head of the fish (fish scale) and arcade. Demarcated peripheral (dependent) of rod still looks clear and without gaps as well as the rod is not porous, but another studies shown there is a gap between the prism enamel that called interprismatic. ${ }^{30}$

Changes in the structure of the prism pattern seen in the SEM observations in this study generally show changes in the pattern of the enamel structure begins at the peripheral part and continues to head the prism, then extends along the lateral edge, and eventually spread to the inferior region and affect cervical rod cores. This statement is in accordance with the results on SEM studies on the prism enamels with multiple treatments using acids and fluor. ${ }^{31}$ Based on this study, it can be proved that prism structure pattern on the enamel surface showed an increase prism structure because of the addition of fluor ions. Thus, it can be stated that the substitution of fluor ions can affect the pattern of enamel surface prism structures, especially in the core and peripheral rods.

\section{CONCLUSION}

The exposure of coffee and black tea affected prism pattern. Fluor ions that contain in black tea affect the better pattern of enamel surface prism structures, especially in the core and peripheral rods.

\section{REFERENCES}

1. Indonesian Plantation Research Institute. Tea Prospects in Indonesia as a Functional B everage. K ustamiyati, B ambang. 7 A gustus 2006. 19 November 2010. http://www.ipard.com/ art_perkebun/ A ug 02-06_Kb.asp.
2. Emekli EA, Y arata, A, A kyuzb S. Fluoride levels in various black tea, herbal, and fruit infusions consumed in Turkey. Food Chem Toxicol 2009 Jul;47(1):1495-98.

3. Cabrera C, A rtacho R, Gimenez R. B eneficial effect of tea. J A m Coll Nutr 2006 A pr;12(1):25(2):79-99.

4. Anila P, Kori S. Can coffee prevent caries. J Conserv Dent 2009;12(1):17-21.

5. Popkin B, A mstrong L, B ray G, C aballero B , F rei B, W illett W. $A$ new proposed guidance system for beverage consumption in the U nited States. A m J Clin N utr 2006;83(3):529-42.

6. Signoretto $C$, Bianchi F, Burlacchini G, Sivieri F, Spratt D, Canepari $P$. D rinking habits are associated with changes in the dental plaque microbial community. J Clin Microbiology 2010;48(2):347-56.

7. Hamilton T, Miller JMT. A nti-cariogenic properties of tea. J Med M icrobiol 2001;50:299-302.

8. Tenuta M , Cury J. Fluoride: Its role in dentistry. B raz Oral Res 2010;24(1):9-17.

9. Smith D. High fluoride levels in tea (2007). 1 December 2010. A vailable from http://www.suitel01.com.

10. U nited States. Department of A griculture. Fluoride database of selected beverages and foods. December 2005. 1 December 2010. available from http://www.ars.usda.gov.

11. Raw earthliving. Teamay contain morefluoridethan oncethought, research shows fluoride content in tea. 3 December 2010. A vailable from: http://www. rew earthliving.wordpress.com.

12. Donna $\mathrm{W}, \mathrm{H}$ arold $\mathrm{H}$, J arvis C. Comparison of fluoride content in caffeinated, decaffeinated and instant coffee. Fluoride Research Report 1996;29(3):147-50.

13. M athai $M$, Shozo $T$. Structures of biologcal minerals in dental research. J Res Natl Inst Stand Technol 2001;106(6):1035-44.

14. B ath-B alogh M , Fehrenbach J M. Dental embriology, histology and anatomy (2nd ed). St L ouis: Elsevier Saunders 2006:p403.

15. Baldassarri $M, M$ argolis HC, B eniash E. Compositional determinants of mechanical properties of enamel. J Dent Res 2008;87:645-49.

16. Godoy GF, John HM. M aintaining the integrity of enamel surface. J A m Dent Assoc 2008;139(2):25-34.

17. Cate $T$, Featherstone $J$. ' $M$ echanistic aspects of interactions between fluoride and dental enamel.' J Dent Res 1991;2(3): 283-96.

18. Chen H, Czaska A, Spencer N, M ansfield J, Robinson C, Clarkson B. Effect of systemic fluoride and fluoride treatment on enamel crystals. J Dent Res 2006;85(11):1042-45.

19. Okazaki M, Legeros R. Properties of heterogeneous apatites containing. M agnesium, fluoride, and carbonate. Advances in Dent Res 1996;10(2):252-59.

20. Robinson C, Shore RC, Brookes SJ, Stafford S, W ood SR, Kirkham J. The chemistry of enamel caries. J Dent Res 2008;11:481-95.

21. Simpson A, Shaw L, Smith AJ. The Bio-availability of fluoride from black tea. J Dent 2001;29:15-21.

22. Fejerskov O, Kidd E. Dental caries. Oxford: Blackwell Publishing Ltd 2003.

23. A oba T, Fejerskov O. D ental fluorosis: Chemistry and biology. J Dent Res 2002;13(2):155-70.

24. Nelson DG, J ongebloed W, A rends, J. M orfology of enamel surfaces treated with topical fluoride agents: SEM considerations. J Dent Res 1983;62(12):1201-07.

25. Cury J, Tenuta M. Enamel remineralization: Controlling the caries disease or treating early caries lesions. B razillian Oral Res 2009;23(1). 
26. Nichol T, Judd G, Ansell S. A two-stage model for human enamel demineralization as determined by scanning electron microscope analysis. J Dent Res 1973;52(3):487-93.

27. Elliot JC, Wilson RM, Dowker S. A patite structures. Dent Biophys 2002;45:172-81.

28. Jeng Y R, Lin TT, W ong TY, Chang HJ, Shieh DB. Nanomechanical properties of fluoride treated enamel surfaces. J Dent Res 2008;87(4):381-85.

29. Simmelink JW, A brigo SC. Crystal morphology and decal cification patterns compared in rat and human enamel and synthetic hydroxyapatite. J Dent Res 1989;3(2):241-48.

30. Hoffman S, M cewan S, D rew C. Scanning electron microscope studies of treated enamel. J Dent Res 1969;48(6):1234-38.

31. Jima $Y, K$ oulourides $T$. Fluoride incorporation into and retention in remineralized enamel. J Dent Res 1989;68(8):1289-92.

\section{ABOUT THE AUTHORS}

\section{Abdillah Imron Nasution}

Department of Oral Biology, Study of Dentistry Program, Faculty of Medical, A ceh, Indonesia

\section{Basri A Gani (Corresponding Author)}

Postgraduate Student, Department of Oral B iology, Study of Dentistry Program, Faculty of Medical, Aceh, Indonesia, e-mail: basriunoe@yahoo.com

\section{Rini Maulida Pospos}

Department of Oral Biology, Study of Dentistry Program, Faculty of Medical, A ceh, Indonesia 